\title{
Hydrological extremes and security
}

\author{
ZBIGNIEW W. KUNDZEWICZ ${ }^{1,2}$ \& PIOTR MATCZAK ${ }^{1,3}$ \\ 1 Institute for Agricultural and Forest Environment, Polish Academy of Sciences, Bukowska 19, 60-809 Poznań, Poland \\ kundzewicz@yahoo.com \\ 2 Potsdam Institute for Climate Impact Research, Telegrafenberg 31, 14473 Potsdam, Germany \\ 3 Institute of Sociology, Adam Mickiewicz University, Szamarzewskiego 89c, 60-568 Poznań, Poland
}

\begin{abstract}
Economic losses caused by hydrological extremes - floods and droughts - have been on the rise. Hydrological extremes jeopardize human security and impact on societal livelihood and welfare. Security can be generally understood as freedom from threat and the ability of societies to maintain their independent identity and their functional integrity against forces of change. Several dimensions of security are reviewed in the context of hydrological extremes. The traditional interpretation of security, focused on the state military capabilities, has been replaced by a wider understanding, including economic, societal and environmental aspects that get increasing attention. Floods and droughts pose a burden and serious challenges to the state that is responsible for sustaining economic development, and societal and environmental security. The latter can be regarded as the maintenance of ecosystem services, on which a society depends. An important part of it is water security, which can be defined as the availability of an adequate quantity and quality of water for health, livelihoods, ecosystems and production, coupled with an acceptable level of water-related risks to people, environments and economies. Security concerns arise because, over large areas, hydrological extremes - floods and droughts - are becoming more frequent and more severe. In terms of dealing with water-related risks, climate change can increase uncertainties, which makes the state's task to deliver security more difficult and more expensive. However, changes in population size and development, and level of protection, drive exposure to hydrological hazards.
\end{abstract}

\section{INTRODUCTION}

Water has significant implications for security. In particular, hydrological extremes - floods and droughts - can cause serious threats to human life and welfare. They undermine societies' security, understood as freedom from threat and the ability of societies to maintain their independent identity and their functional integrity against forces of change (Buzan 1991).

In this paper, the significance of water extremes for human security is discussed. The concept of security is reviewed in the context of water-related issues. The current knowledge on hydrological extremes - floods and droughts - is summarized, with consideration of the climate change context. Implications of hydrological extremes for governance are also presented.

\section{WATER IN THE CONTEXT OF SECURITY}

The classical concept of security focused on the military capabilities of the state, international relations, and state sovereignty. In recent decades, the concept has extended beyond the traditional interpretation, focused on political and military aspects, to a wider understanding, embracing societal, economic, and environmental aspects (Buzan 1981). Water issues have importance in particular security fields. Societal insecurity appears if any of the substantial elements of a society's identity is threatening survival of the society. Water resources are a necessary element to sustain acceptable levels of welfare and thus they are an important part of security of the society. Security in the economic area is related to the state's responsibility to sustain economic stability. In this respect, economic crises and disturbances caused by hydrological extremes can pose a serious danger to national security. Environmental security is related to the maintenance of ecosystem services, on which a society depends. Environmental threats include sudden events, such as floods, and others, such as droughts, that emerge within longer time spans.

The areas of security are intertwined. Environmental security is linked to economic security, and to the societal one. Water-related issues are relevant to all of them. Water security is an emerging theme (Cook and Bakker 2012, Bakker and Morinville 2013) and four research areas can be distinguished: (a) water security focused on water quantity and availability and water quality; (b) water-related hazards and vulnerability; (c) water as a basic need - linked to the development issues, such as welfare, food security, poverty, etc. (Grey and Sadoff 2007, Falkenmark 2001); and (d) the 
sustainability related issues. Cook and Bakker (2012) suggest that an integrative approach to water security, with governance as a central issue, is promising in terms of both research and policy.

Threats caused by hydrological extremes, the focus of this paper, are accelerated by climate change. This is self-explanatory with respect to water quantity, and less well known for water quality. However, higher water temperatures and hydrological extremes, floods and droughts, exacerbate water pollution - from sediments, nutrients, dissolved organic carbon, pathogens, pesticides and salt, as well as thermal pollution, with possible negative impacts on ecosystems, human health, and water system reliability and operating costs (Bates et al. 2008). In addition, sealevel rise extends areas of salinization of groundwater and estuaries, resulting in a decrease of freshwater availability for humans and ecosystems in coastal areas.

Difficulties in raising sufficient and timely capital to replace or repair damaged infrastructure and restore livelihoods after major disasters lead to an increased challenge to societies' security in the environmental, social, economic, and even military sense. At the same time, managing water in order to decrease water destructive features and to increase its productive powers, is an urgent demand (Grey and Sadoff 2007).

The concept of securitization embraces the process of security as a socially defined phenomenon (Trombetta 2011). In this respect, security efforts in certain areas (natural disasters, terrorism, defence, pandemics, etc.) are based on a social contract between citizens and the state, obliged to minimize impacts from threats (Matczak and Kundzewicz 2015). Dealing with hydrological extremes involves both adaptation (increasing the resilience) and building capacity to manage when a disaster actually occurs. Emergency and crisis management structures are the state's institutions specialized in threat preparation and defense. However, the scope of the responsibilities of such systems, their operational capacity and organizational structure depend on public attitudes and expectations, the government's priorities and on availability and recognition of scientific knowledge.

Social attitudes vary among societies and in time. Figure 1 illustrates attitudes of European societies with respect to perception of the composite problem of poverty, hunger and lack of drinking water as the most serious global problem.

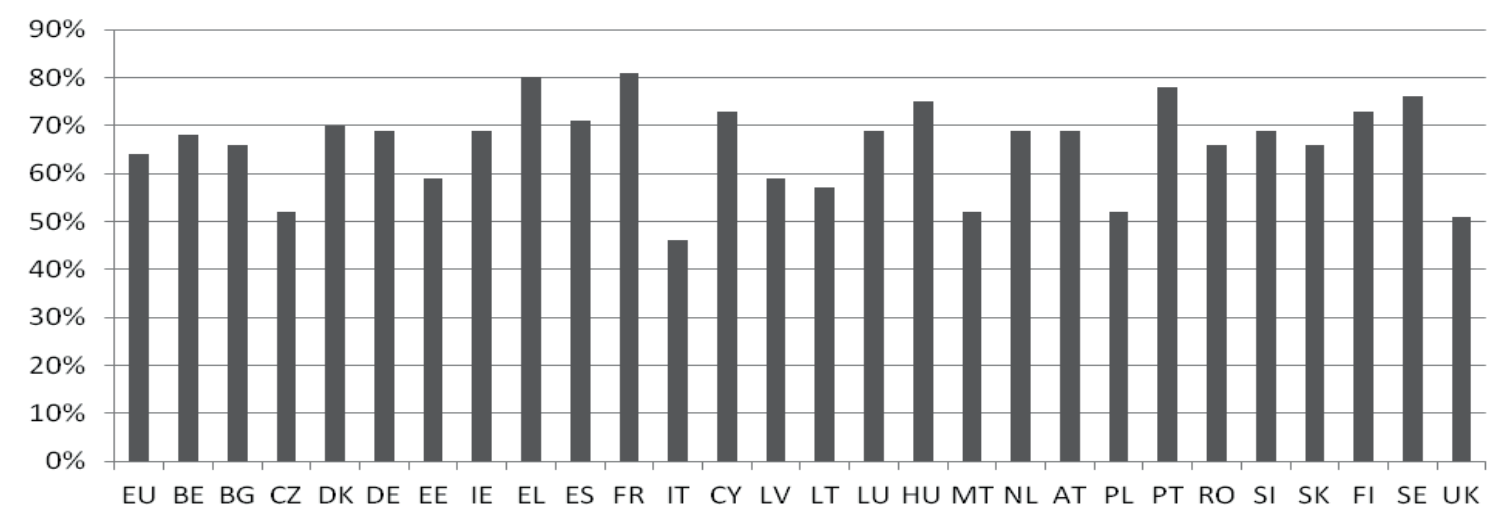

Fig. 1 The percentage of respondents who indicated "Poverty, hunger and lack of drinking water" as an answer to the question: "Which of the following do you consider to be a single most serious problem facing the world as a whole?". Based on: Eurobarometer 372, Climate change (2011).

Beside inter-societal diversity, public perception of risks has peculiarities. The large literature on risk perception shows various biases of risks as perceived by people (Slovic 2000). Moreover, perception also changes in time. A single event can make a difference. Improved reporting of disasters (so-called CNN effect) has affected societal perceptibility of disasters.

Also, governmental action can differ. In times of economic austerity, governments' abilities are limited (Mechler et al. 2010). Although impacts caused by floods and droughts are to be tackled by states, the resources spent and invested depend on the budget constraints. Thus, actual security is a matter of political decision-making. Projects related to water security inevitably become politicized as different stakeholders seek to promote their interests (Warner 2011). 


\section{SECURITY RELATED TO WATER}

\section{Threats to water security}

Water is needed, in high quantities, to support life, and in every human activity. Access to safe freshwater has become an essential human right.

As noted by Vörösmarty et al. (2010), nearly $80 \%$ of the world's population is exposed to high levels of threat to water security. Massive investment in water technology enables more affluent nations to offset high stressor levels without remedying their underlying causes, whereas less wealthy nations remain vulnerable. Moreover, water-management strategies aimed at improving human water security, such as building dams to provide access to water-starved regions, often detrimentally affect wildlife, e.g. migrating fish, which also depend on freshwater resources (Gilbert 2010). Climate change significantly reduces renewable surface water and groundwater resources in most dry regions (Döll et al. 2015). This exacerbates competition among the water users and sectors (agriculture, ecosystems, settlements, industry, and energy production).

However, the paradigm that dry areas will get drier (and wet areas will get wetter), a standard catchphrase frequently used in studies and assessments of historical and future climate change, is now being challenged by the findings of Greve et al. (2014). The concept that dry regions dry out further as the climate warms has been proposed as a simplified summary of expected as well as observed changes over land, although this concept is mostly based on oceanic data. Analysis of many combinations of various hydrological datasets of historical land dryness changes, covering the period from 1948 to 2005, show that for more than three-quarters of the global land area, robust dryness changes cannot be detected. Greve et al. (2014) concluded that aridity changes over land, where the potential for direct socio-economic consequences is highest, have not followed a simple intensification of existing patterns.

A modelling study by Gerten et al. (2013) demonstrates at what level of global mean temperature rise $\left(\Delta T_{\mathrm{g}}\right)$ regions are projected to be exposed to significant decreases of freshwater availability. At present, about 1.3 billion people already live in water-scarce regions. The modelling results suggest that mean global warming levels of $2^{\circ} \mathrm{C}, 3.5^{\circ} \mathrm{C}$ and $5^{\circ} \mathrm{C}$ may expose an additional $8 \%, 11 \%$ and $13 \%$, respectively, of the world population to new or aggravated water scarcity. The results suggest nonlinear growth of impacts along with the warming, and highlight regional disparities in impact magnitudes and critical warming levels.

Mountain glacier shrinkage creates a significant risk to more than a billion people using glacierbased water resources. Mountain glaciers serve as convenient water towers on which freshwater supply to inhabitants of many large towns depends. When mountain glaciers disappear, it will be necessary to store precipitation water in artificial reservoirs that will have to be constructed. This is a large, expensive and time-consuming task, with huge environmental and social impact (Bates et al. 2008).

Water security is a growing problem. The water-related Millennium Development Goals target (halving the number of people without access to safe freshwater by 2015) is not met. The number of those without access to safe freshwater is still very high - perhaps 783 million people (http://www.unwater.org/water-cooperation-2013/water-cooperation/facts-and-figures/en/). Moreover, models of climate change impacts show that water security problems are not going to be solved - on the contrary, they will likely increase.

\section{Hydrological extremes}

Hydrological extremes, floods and droughts, jeopardize human security and have adverse impact on societal livelihood and welfare. Hence, they can undermine societal and economic security, posing serious challenges to the state, which needs to cope with them.

Economic losses caused by floods and droughts have been on the rise. Fatality rates and relative economic losses (expressed as a proportion of gross domestic product, GDP) are typically higher in developing countries than in developed countries. This has grave security implications. In 19702008 , over $95 \%$ of natural-disaster-related deaths occurred in developing countries (IPCC 2012). 
Damage associated with large natural disasters can be typically of the order of less than $0.1 \%$ of GDP for high-income countries, and about $1 \%$ of GDP for middle-income countries. In small, exposed countries, particularly in small-island developing states, losses expressed as a percentage of GDP have been particularly high, exceeding $1 \%$ in many cases.

Hydrological disaster risk results from the interaction of hazard (exceedence probability of a flood or drought of concern), exposure (presence of people, ecosystems and assets in places and settings that could be adversely affected by the hazard) and vulnerability (predisposition to be adversely affected) of human society and natural ecosystems. Risk is often estimated as the probability of occurrence of hazardous events multiplied by the impacts that ensue if these events or trends do occur (IPCC 2012). The risk is shaped by climate (subject to natural variability and the ongoing anthropogenic climate change) and development - particularly land-use patterns. Important correlations have been noted between ENSO (E1 Niño-Southern Oscillation) events and hydrological extremes. During a strong El Niño or La Niña phase, there is a fairly high probability that some regions become drier than usual (with substantial drought risk) and others - wetter than usual (with substantial flood risk). Disaster risk management and climate change adaptation are needed that reduce exposure and vulnerability to weather and climate events and thus reduce disaster risk, as well as increasing resilience to the residual risk that cannot be eliminated.

Although the significance of natural hazards and climate change as sources of insecurity is widely acknowledged, the comprehensive understanding is still missing. Complexity of the natural phenomena and the changing nature of the security systems makes it difficult to offer a simple interpretation of the environmental threats to security. The variety of political regimes and geographic conditions poses a challenge to our comprehension of environmental security and security policy prescriptions.

\section{FLOODS UNDERMINE SECURITY}

There is no such thing as absolute security from floods for people living in the vicinity of river basins. Since the dawn of civilization, destructive floods have jeopardised settlements located near rivers. Floods have devastated cultural landscapes and undermined sustainable development by breaking continuity (Kundzewicz 1999). Despite developments in technology and extensive investment in flood protection and preparedness, flood occurrences as well as material damages are not decreasing.

In order to provide more security, risk needs to be reduced. Several factors may influence a scale of flood risk. Changes in socio-economic systems are very important drivers, e.g. increasing exposure of population and assets (due to increase of property value, flood plain development, and growing wealth accumulated in flood-prone areas, hence increase of damage potential), and degraded awareness about natural risks (due to lifestyles that separate people from natural processes). Changes in climate may lead to higher frequency and/or intensity of the flood events. In addition, changes in hydrological and terrestrial systems drive the flood risk (via land-use change, urbanization, deforestation and river regulation - channel straightening and shortening, constructing embankments).

\section{Observations}

About 800 million people worldwide are currently living in flood-prone areas and about 70 million of those people are, on average, exposed to floods each year. The highest relative share of an economy exposed to floods can be found in Cambodia, while Bangladesh is the country with the highest number of people exposed to floods, both in absolute and in relative terms (Kundzewicz et al. 2014). Since 1980, over $95 \%$ of flood-related deaths have occurred in developing countries and $75 \%$ in southern, southeastern and eastern Asia (Handmer et al. 2012).

There have been statistically significant increases in the number of heavy precipitation events in more regions than there have been statistically significant decreases, but there are strong regional and subregional variations in the trends (Seneviratne et al. 2012). Frequency and intensity of heavy precipitation have grown in many, but not all, areas of the globe. However, no gauge-based evidence 
has been observed so far for a clear and ubiquitous climate-driven change in the magnitude/ frequency of river floods. Recent detection of trends in extreme precipitation and discharge in some catchments implies greater risks of flooding at the regional scale.

The global mortality risk from floods increased from 1980 to 2000, but is now stabilizing and even reducing, due to a compensation of the increase in exposure by a significant decrease in vulnerability. Trends in the vulnerability of what is exposed are variable by location, and the global trend is largely influenced by China, where vulnerability to floods has decreased over the past decade (in particular due to "vertical urbanization"), cf. Kundzewicz et al. (2014).

Reported flood damages (adjusted for inflation) have more than trebled since the 1980s. Economic, including insured, flood disaster losses are higher in developed countries, while fatality rates and economic losses expressed as a proportion of GDP are higher in developing countries.

Economic losses from floods have increased considerably, but with large spatial and interannual variability. Global flood disaster losses reported over the last few decades mainly reflect monetized direct damages to assets.

Current studies indicate that increasing exposure of population and assets, and societal factors related to population and economic growth, rather than anthropogenic climate change, is responsible for the past increase in flood losses (Handmer et al. 2012, Kundzewicz et al. 2014).

Kundzewicz et al. $(2007,2008)$ and Bates et al. (2008) argue that climate change (and the observed increase in precipitation intensity) might already have had an impact on floods. The physical reasoning suggests that increases in heavy rainfall would contribute to increase in raingenerated local floods. However, models and observations do not lead to a clear conclusion in terms of climate change impact on the frequency and scale of floods. In general, it has not been possible to rigorously attribute rain-generated peak streamflow trends to anthropogenic climate change, except for the study by Pall et al. (2011).

\section{Projections}

Projected changes indicate that the frequency of heavy precipitation or proportion of total rainfall from heavy falls will likely increase (Seneviratne et al. 2012), even in some (but not all) regions with projected decreases of total precipitation. More frequent heavy precipitation events projected over most regions of the world affect the risk of rain-generated floods. In future, flash flooding and urban flooding may become more frequent and more severe.

However, confidence in the projected magnitude of change in precipitation totals, frequency and intensity, along with snow cover, snow melt and soil moisture (i.e. variables relevant for causing changes in floods), and - over some regions - even in the sign of change, may be low.

Recent global flood projections based on an ensemble of climate, hydrology and land surface models (Dankers et al. 2013, Hirabayashi et al. 2013) show that flood hazards increase over about half of the globe, but with great regional and local variability. There is a large uncertainty arising from many sources, including socio-economic scenarios, variation between climate model sensitivities, methods of downscaling and bias reduction, and hydrological models. Projected flood damages vary greatly between models and from region to region.

Studies that project future flood losses and casualties indicate that, when no adaptation is undertaken, future anthropogenic climate change is likely to lead to increasing flood losses, alongside the increase in exposure linked to ongoing economic development. Where rapid urbanization also brings inadequately engineered in-city drainage infrastructure, its effect can promote rather than decrease losses. In general, human modifications of watersheds and changing their runoff characteristics (via decreasing of water storage volume and increase of the runoff coefficient) increase flood risk.

The impacts of changes in flood characteristics are highly dependent on how climate changes, but there is low confidence in specific projections of changes in flood magnitude or frequency in the future. Also, increase of the flood damage potential increases flood risk.

It is necessary to jointly consider landscape changes that affect flood response, location and protection of people and property at risk, as well as changes in flood risk due to changes in climate. 
All these factors are of critical importance to the future of flood hazard and economic losses due to flooding.

\section{Flood risk reduction}

There exists a roster of strategies for reducing flood losses. A category of strategies aimed at keeping water away from people includes flood defences, as well as flood flow improvement and retention. Another strategy - flood risk prevention - aims at keeping people and wealth away from water. However, we have to be aware that there is a possibility of coincidence of destructive abundance of water and a considerable damage potential at the same time and place. Hence, we have to consider the residual risk of the situation when the attempts to keep water away from people, and to keep people and wealth away from water, fail.

Instead of striving to build a fail-safe system that never fails we should be aware that every system may fail. However, if the system fails, it should fail in a safe way (safe-fail) and recover after failure. This is the essence of the notion of resilience. Since a flood protection system guaranteeing absolute safety is an illusion, a change of paradigm is needed: it is necessary to live with the awareness of the possibility of floods. Kundzewicz and Takeuchi (1999) give examples of implementation of these notions. Rather than trying, in vain, to eradicate floods, one could accommodate them in one's planning and learn to live with them. No matter how high the design flood for a structural defence is, there is always a possibility of having a greater flood, inducing losses. It is necessary to be prepared what to do then - how to accommodate the residual risk in our planning.

The concept of risk can be illustrated in the context of structural flood defences - dikes, that may provide excellent protection against more frequent (small to medium) floods, yet their existence creates a false feeling of absolute safety and may trigger development on flood plains. If a dike breaks during an extreme flood, this defence does not act as a protection, but rather as an amplifier of destruction; flood losses without a dike would have been lower.

Sustainable development as the guidance for public policies assumes a built-in mechanism of maintenance of resilience against surprises and shocks, such as a large flood. A common interpretation of sustainable development is that civilization, wealth (human and natural capital) and environment (built and natural) should be relayed to future generations in a non-depleted shape. Within the social pillar of sustainable development, fairness or equity imply that flood protection, translating into a feeling of security, should be extended to all members of the society. Yet, difference in vulnerability to floods even between neighbouring households can be enormous, especially in less developed countries.

Flood protection measures can be structural ('hard') or non-structural ('soft'). Dams and flood control reservoirs, diversions, etc., belong to the category of structural flood protection measures. Constructing reservoirs where the excess water can be stored allows streamflow regulation and helps alleviate the flood problem by flattening destructive flood peaks.

A sample of possible non-structural (soft) means includes:

- zoning, regulation for flood hazard areas development leaving flood plains with low-value infrastructure, e.g. vegetation occasionally flooded;

- a system of flood forecasting, warning (issuing and dissemination), evacuation, relief and postflood recovery;

- flood insurance, that is division of risks and losses among a higher number of people over a long time; and

- capacity building (improving flood awareness, understanding and preparedness), enhancing participatory approaches.

An important flood protection measure is the source control that is watershed management, including land use and soil conservation to minimise surface runoff, erosion and sediment transport. The idea of source control - catching water where it falls - is implemented by measures such as enhancing infiltration (reducing impermeable area, enhancing pervious pavements and parking lots), 
and local storages (ponds, building and groundwater storages; cf. Kundzewicz and Takeuchi 1999). Enhancing retention counteracts the adverse effects of urbanization (growth of flood peak, drop in time-to-peak of a hydrograph, drop in roughness coefficient and in storage potential) and of channelization (faster flood conveyance through shortened and straightened rivers).

The linkages between enhanced greenhouse forcing and flood phenomena are complex and inadequately understood. Hence, it is important that society does not lose focus on the things we already know for certain about floods and how to mitigate and adapt to them. Blaming climate change for flood losses makes flood losses a global issue that appears to be out of the control of regional or national institutions (Kundzewicz et al. 2014). It is clear that current trends in human activity on the landscape continue to cause an increase in flood damages, hence decreasing or reversing this trend, e.g. by getting out of the harm's way, requires substantial attention. Coping better with existing extremes augurs well for a more demanding, yet uncertain, future.

\section{DROUGHTS UNDERMINE SECURITY}

The notion of drought should not be confused with aridity, where dryness is a normal condition and freshwater is always in short supply.

The term drought (cf. Bates et al. 2008) may refer to a meteorological drought (precipitation deficit), agricultural drought (soil moisture deficit), hydrological drought (surface water and groundwater deficit), and environmental drought (a combination of the above). The socio-economic impacts of droughts may arise from the interaction between natural conditions and human factors such as changes in land use, land cover, and the demand for and use of water. Excessive water withdrawals can exacerbate the impact of drought. There are various drought indices, such as the number of consecutive dry days (or days with precipitation totals below a threshold of $0.1 \mathrm{~mm}$ ), the Standardized Precipitation Index (SPI), Palmer Drought Severity Index (PDSI), and Standardized Runoff Index (SRI).

Droughts affect rain-fed agricultural production as well as water supply for domestic, industrial and agricultural purposes. The number of people exposed to droughts, globally, extends to billions.

Droughts may have become more widespread, more intense and longer in many regions around the globe, due to reduced land precipitation and/or warming that enhances evapotranspiration and drying.

Because drought is a complex variable, it is incompletely represented by commonly used drought indices. Hence, discrepancies in the interpretation of changes can result. Hartmann et al. (2013) review the contradictory results of change detection presented by different researchers, using different drought indices and different data periods. Since the 1950s some regions of the world (e.g. southern Europe and western Africa) have experienced more frequent meteorological and agricultural droughts. However, results of trend detection in hydrological drought do not support the general hypothesis of ubiquitous increasing severity or frequency of drought conditions.

Dai (2011) found a general global increase in drought, although with substantial regional variation and individual events dominating trend signatures in some regions (e.g. the 1970s prolonged Sahel drought and the 1930s drought in the USA and Canadian Prairies), but these findings may be different from those of some other studies, for other data periods, regions and indices (Hartmann et al. 2013).

A multi-decadal train of regional droughts in the Sahel commencing in the 1960s, believed to be climatically driven by the Atlantic Multi-decadal Oscillation (AMO) - and augmented by people - has had devastating effects. Northeast Brazil has also been struck by many droughts.

Drought impacts at continental and smaller scales are difficult to assess because they vary greatly with the local hydrological conditions and water-management practices (Handmer et al. 2012). More frequent droughts due to climate change together with an increase of population may challenge existing water management systems, placing even the domestic water supply at risk (Döll et al. 2015).

The 2003 heat-wave in much of Europe (cf. Bates et al. 2008), attributable to global warming, was accompanied by annual precipitation deficits of up to $300 \mathrm{~mm}$. This drought contributed to 
detectable reduction in gross primary production of terrestrial ecosystems over Europe, and record low levels of rivers resulted in disruption of inland navigation and irrigation. The drought had grave consequences for hydropower - little water was available for power plant cooling. Because river water temperatures were high, discharging the water warmed-up by the cooling process in power stations back to surface waters was not acceptable due to exceedence of environmental safety standards.

Bates et al. (2008) noted that the proportion of land surface in extreme drought at any one time will likely increase, in addition to a tendency for drying in continental interiors during summer, especially in the sub-tropics, and low and mid-latitudes. This indicates a greater risk of droughts in these regions. Droughts associated with this summer drying could result in regional vegetation dieoff. The frequency of meteorological droughts (less rainfall) and agricultural droughts (less soil moisture) in presently dry regions will likely increase in the future. However, confidence regarding quantitative changes in future drought hazards is not high because model-based projection of future climatic and hydrological extremes is more uncertain than the projection of mean conditions.

A decrease in summer precipitation in southern and central Europe, accompanied by rising temperatures (which enhance evaporative demand), would inevitably lead to both reduced summer soil moisture and more frequent and intense droughts (Bates et al. 2008).

Adaptation options designed to ensure water supply during drought conditions include both supply-side (providing more water) and demand-side strategies that improve water-use efficiency, e.g. by recycling water. Use of economic incentives, including metering and pricing, to encourage water conservation, development of water markets and implementation of virtual water trade, holds considerable promise for water savings. Supply-side strategies generally involve increases in storage capacity, conjunctive use of surface water and groundwater, and water transfers. Increase of storage of water and flow regulation are advantageous for floods and droughts - catching water when abundant and discharging it when in short supply. An important 'soft' drought adaptation measure is drought forecasting that may trigger activities alleviating the adverse impacts.

\section{FINAL REMARKS}

Hydrological extremes present a growing pressure to security. Changes in population size and development, and the level of protection, strongly influence changes in exposure to floods and droughts. The exposed population and assets have increased more rapidly than the total population or economic growth.

The potential increases in the number and severity of natural disasters pose a challenge to governments responsible for relief and recovery. Adjusting the state's capabilities is a difficult task due to the complexity and related uncertainties, and the cross-border and global characteristics of the threats.

Hydrological extremes and the threats caused by them depend on natural processes as well as social and economic factors. Increasing vulnerability, exposure, or severity and frequency of climate events increase disaster risk. Security concerns arise because, over large areas, floods and droughts may become more extreme (more frequent and more severe), adversely affecting water quantity and quality. The impacts of floods and droughts are projected to increase even when the hazard remains constant, due to increased exposure and vulnerability (Kundzewicz et al. 2014).

In the case of climate change, general impacts can be pointed out as relevant to security. Climate change can intensify existing environmental problems related to drought, water scarcity, and floods. In the developing countries it can increase vulnerability, poverty and malnutrition. In countries with weak institutions, the capabilities to cope with tensions may be additionally undermined. As the frequency and scale of negative impacts is supposed to increase with the warming, greater risks for security can be anticipated.

Climate change may have impact on resources, including water resources, and this can lead to international and national tensions related to the distribution of water resources, jeopardizing security. Also climate change-related migration may threaten security. Hence, climate change can lead to social and political destabilization. It is certain that the negative consequences of climate change are not uniformly distributed - there are (and there will be) winners and losers. 
However, projections of climate change impacts on freshwater resources are uncertain. Clearly, climate models - the principal tool used for projections - are not ready for prime time (Kundzewicz and Stakhiv, 2010). They cannot reliably reconstruct past precipitation and massive bias reduction is necessary that does not build confidence. Projections are not only scenario specific, but also largely model specific.

Concerning the cross-border and global characteristics of threats, climate change is a good example of how interlinked risks are between regions and countries. The states' efforts within their jurisdictions can be undermined by activities in other parts of the world. Thus international coordination is needed. This has proved to be very difficult, as the global climate negotiations aiming to address global warming by limiting greenhouse gas emissions, show. Indeed, 19 large (recently attended by more than 10000 participants each) conferences of parties of UNFCCC have been held. However, despite all these climate summits, climate policy does not deliver the necessary results the atmospheric concentrations of greenhouse gases have been rising, and the warming and accompanying climate change impacts go on.

Nevertheless, some initiatives addressing the need to reduce the risk of floods and droughts are already in place, such as the Hyogo Framework for Action - Building the resilience of nations and communities to disasters (a 10-year plan to make the world safer from natural hazards), the Floods Directive and the Solidarity Fund of the European Union, as well as international aid and technical assistance in emergency situations. The Asia-Pacific region, where climate change is spectacular and social change (population and economic growth) is the most dynamic in the world, is strongly disaster-prone. However, there are fine examples (Takara 2013) of mobilizing international cooperation for disaster risk reduction, capacity building and strengthening the science-policy interface.

Notwithstanding the climate change effect, increasing exposure of people and assets has been the major cause of changes in disaster losses.

Acknowledgements The research leading to this paper has received funding from the European Commission under the EU FP7 STAR-FLOOD Project (STrengthening And Redesigning European FLOOD risk practices: Towards appropriate and resilient flood risk governance arrangements), grant agreement no. 308364 .

\section{REFERENCES}

Bakker, K., and Morinville, C. (2013) The governance dimensions of water security: a review. Phil. Trans. R. Soc. A. 371, 20130116, doi:10.1098/rsta.2013.0116.

Bates, B. C., et al. (ed.) (2008) Climate Change and Water. Technical Paper of the Intergovernmental Panel on Climate Change. IPCC Secretariat, Geneva, 210 pp.

Buzan, B. (1981) People, States and Fear: An Agenda for International Security Studies in the Post-Cold War Era. Hertfordshire.

Buzan, B. (1991) New patterns of global security in the twenty-first century. International Affairs 67(3), 432-433.

Buzan, B., et al. (1998) Security. A New Framework. Harvester Wheatsheaf, Hemel Hempstead.

Cook, Ch. and Bakker, K. (2012) Water security: Debating an emerging paradigm. Global Environmental Change 22, 94-102.

Dai, A.G. (2011) Drought under global warming: A review. Climate Change 2, 45-65.

Dankers, R., et al. (2013) A first look at changes in flood hazard in the ISI-MIP ensemble. Proceedings of the National Academy of Sciences of the United States of America 111(9), 3257-3261.

Döll, P., et al. (2015) Integrating risks of climate change into water management. Hydrol. Sci. J. 60(1), 4-13.

Eurobarometer (2011) Climate change, report 372.

Falkenmark, M. (2001) The greatest water problem: The inability to link environmental security, water security and food security. International Journal of Water Resources Development 17(4), 539-554, doi:10.1080/07900620120094073.

Gerten, G., et al. (2013) Asynchronous exposure to global warming: freshwater resources and terrestrial ecosystems. Environmental Research Letters 8(3), 12, doi:10.1088/1748-9326/8/3/034032

Gilbert, N. (2010) Balancing water supply and wildlife. Nature doi:10.1038/news.2010.505.

Greve, P., et al. (2014) Global assessment of trends in wetting and drying over land. NatGeosci. 7(11), 716-721.

Grey, D. and Sadoff, C.W. 2007. Sink or Swim? Water security for growth and development. Water Policy 9, 545-571.

Handmer, J., et al. (2012) Changes in impacts of climate extremes: human systems and ecosystems. In: Managing the Risks of Extreme Events and Disasters to Advance Climate Change Adaptation (Field, C.B., et al., eds.). A Special Report of Working Groups I and II of the Intergovernmental Panel on Climate Change (IPCC). Cambridge University Press, Cambridge, UK, and New York, NY, USA, pp. 231-290. 
Hartmann, D.L., et al. (2013) Observations: atmosphere and surface. In: Climate Change 2013: The Physical Science Basis. Contribution of Working Group I to the Fifth Assessment Report of the Intergovernmental Panel on Climate Change (Stocker, T.F., et al., eds). Cambridge University Press, Cambridge, United Kingdom and New York, NY, USA.

Hirabayashi, Y., et al. (2013) Global flood risk under climate change. Nature Climate Change 3, 816-821.

IPCC (2012) Summary for Policymakers. In: Field, C.B., et al. (eds) Managing the Risks of Extreme Events and Disasters to Advance Climate Change Adaptation, A Special Report of Working Groups I and II of the Intergovernmental Panel on Climate Change, Cambridge, and New York, USA, pp. 1-19.

Kundzewicz, Z.W. (1999) Flood protection - sustainability issues. Hydrol. Sci. J. 44, 559-571.

Kundzewicz, Z.W., et al. (2014) Flood risk and climate change: global and regional perspectives. Hydrol. Sci. J. 59(1), $1-28$.

Kundzewicz, Z.W., et al. (2008) The implications of projected climate change for freshwater resources and their management. Hydrol. Sci. J. 53(1), 3-10.

Kundzewicz, Z.W. and Stakhiv, E. (2010) Are climate models 'ready for prime time' in water resources management applications or is more research needed? Hydrol. Sci. J. 55(7), 1085-1089.

Kundzewicz, Z.W. and Takeuchi, K. (1999) Flood protection and management: Quo vadimus? Hydrol. Sci. J. 44, $417-432$.

Matczak, P. and Kundzewicz, Z.W. (2015) Climate change and natural hazards - implications for Poland's security. Paper submitted to: Przegląd Zachodni.

Mechler, R., et al. (2010) Assessing the Financial Vulnerability to Climate-Related Natural Hazards. World Bank Policy Research Working Paper 5232, Background Paper to the 2010 World Development Report.

Pall, P., et al. (2011) Anthropogenic greenhouse gas contribution to flood risk in England and Wales in autumn 2000. Nature 470 (7334), 382-385. doi:10.1038/nature09762.

Seneviratne, S.I., et al. (2012. Changes in climate extremes and their impacts on the natural physical environment. In: C.B. Field, et al. (eds) Managing the risks of extreme events and disasters to advance climate change adaptation. Special Report of Working Groups I and II of the Intergovernmental Panel on Climate Change (IPCC). Cambridge: Cambridge University Press.

Slovic, P., ed. (2000) The Perception of Risk. London, Earthscan Publications.

Takara, K. (2013) Coping with extreme weather and water-related disasters. In: UNESCO. Free Flow - Reaching Water Security through Cooperation. UNESCO Publishing, Paris, 103-106.

Trombetta, M.J. (2011) Rethinking the securitization of the environment. In: T. Balzacq (ed.) Securitisation Theory: How Security Problems Emerge and Dissolve. Routledge.

Vörösmarty, C.J., et al. (2010) Global threats to human water security and river biodiversity. Nature 467, 555-561, doi:10.1038/nature09440

Warner, J.F. (2011) Flood Planning: The Politics of Water Security. I B Tauris \& Co Ltd. 